\title{
Predictors of transition in smoking stages in Iranian adolescents: latent transition analysis
}

\author{
A. Mohammadpoorasl, ${ }^{1}$ S. Nedjat, ${ }^{2,3}$ A. Fakhari, ${ }^{4}$ K. Yazdani ${ }^{2}$ and A. Fotouhi ${ }^{2}$
}

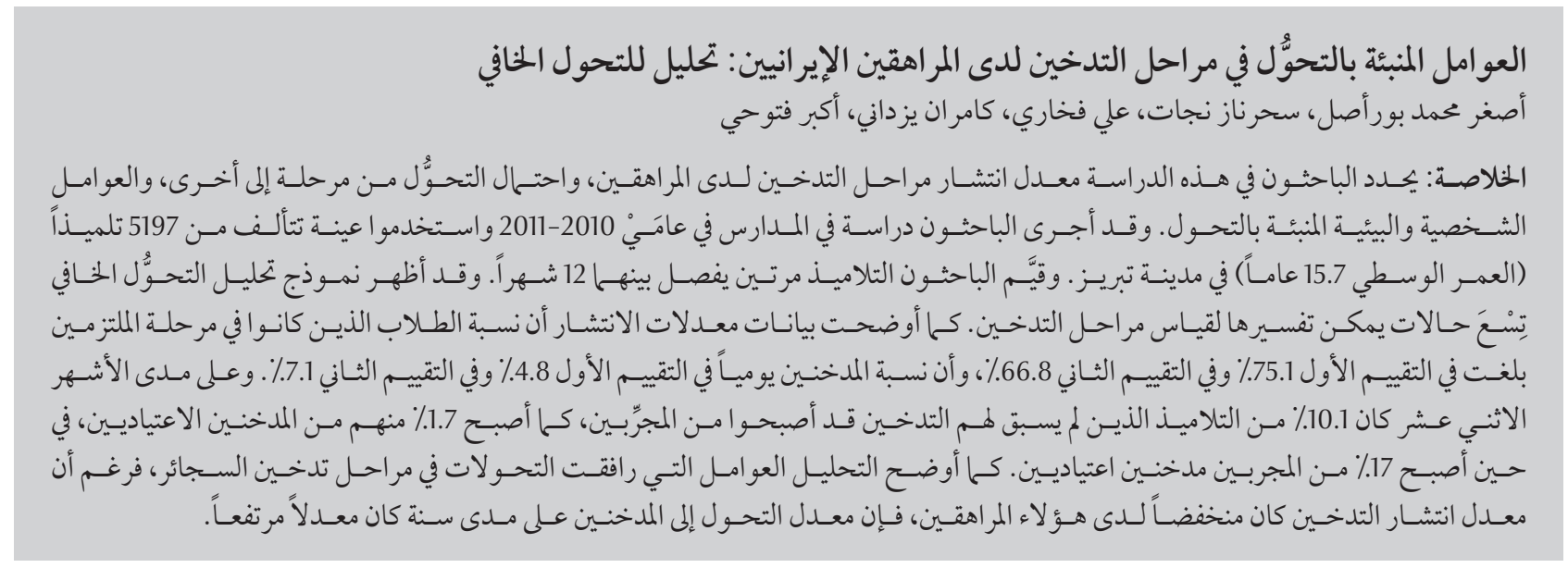

ABSTRACT This study determined the prevalence of smoking stages in adolescents, the probability of transition across stages and the personal and environmental predictors of transition. A school-based study was conducted in 2010-11 using a random sample of 5197 students (mean age 15.7 years) in Tabriz city. The students were evaluated twice, 12-months apart. The latent transition analysis model revealed 9 interpretable statuses for the measurement of smoking stages. Prevalence data showed that at the first and second assessments $75.1 \%$ and $66.8 \%$ of students respectively were in the committer stage, while $4.8 \%$ and $7.1 \%$ respectively were daily smokers. Over 12 months, $10.1 \%$ of the never smokers became experimenters and $1.7 \%$ became regular smokers, while $17.0 \%$ of experimenters became regular smokers. The analysis also showed factors associated with transitions in cigarette smoking stages. Although the prevalence of smoking was low in our adolescents, the rate of becoming a smoker over 1 year was high.

Facteurs prédictifs de transition entre les stades de consommation de tabac chez des adolescents iraniens : une analyse des transitions latentes

RÉSUMÉ La présente étude a déterminé la prévalence des stades de consommation du tabac chez des adolescents, la probabilité de transition entre les différents stades et les facteurs prédictifs de transition personnels et environnementaux. Une étude a été menée en milieu scolaire en 2010 et 2011 à partir d'un échantillon aléatoire de 5197 élèves (âge moyen : 15,7 ans) dans la ville de Tabriz. Les élèves ont été évalués à deux reprises, à 12 mois d'intervalle. Le modèle d'analyse des transitions latentes a permis de dégager neuf statuts interprétables afin de mesurer les stades de consommation de tabac. Les données sur la prévalence ont révélé que lors de la première et de la deuxième évaluation, $75,1 \%$ et $66,8 \%$ des élèves respectivement étaient des non-fumeurs décidée à ne pas commencer, tandis que $4,8 \%$ et $7,1 \%$ respectivement étaient des fumeurs quotidiens. Sur une période de 12 mois, 10,1\% des personnes n'ayant jamais fumé ont expérimenté le tabac et 1,7 \% sont devenus des fumeurs réguliers, tandis que $17,0 \%$ des personnes ayant expérimenté le tabac sont devenus des fumeurs réguliers. L'analyse a mis en évidence des facteurs associés aux transitions entre les stades de consommation de tabac. Si la prévalence du tabagisme était faible chez nos adolescents, le taux de transition vers le statut de fumeur sur une période d'un an était en revanche élevé.

'Department of Human Nutrition and Food Safety, School of Public Health, Qazvin University of Medical Sciences, Qazvin, Islamic Republic of Iran (Correspondence to A. Mohammadpoorasl:poorasl@yahoo.com).

${ }^{2}$ Department of Epidemiology and Biostatistics; ${ }^{3}$ Knowledge Utilization Research Centre, School of Public Health, Tehran University of Medical Sciences, Tehran, Islamic Republic of Iran.

${ }^{4}$ Clinical Psychiatry Research Centre, Tabriz University of Medical Sciences, Tabriz, Islamic Republic of Iran.

Received: 13/06/13; accepted: 12/12/13 


\section{Introduction}

Smoking is one of the leading causes of preventable death globally, with substantial health-related economic costs to society $[1,2]$. Despite differences in smoking prevalence in different parts of the world, the age at onset of smoking is fairly similar and most smokers begin smoking before 18 years of age [3]. Age at smoking initiation is one of the most important determinants of future tobacco dependence, chance of cessation and risk of adverse health outcomes [4-7]. A major concern is that the age of initiating smoking is decreasing in both developed and developing countries $[8]$ including the Islamic Republic of Iran. This emphasizes the importance of research on smoking in adolescents.

The prevalence of tobacco use among adolescents varies in different parts of the world. Based on the findings of the Global Youth Tobacco Survey (1999-2001) in 75 regions from 43 countries, the prevalence of smoking experience and current smoking among adolescents aged $13-15$ years were $33 \%$ and $14 \%$ respectively [9]. In the Islamic Republic of Iran the prevalence of cigarette smoking among adolescents has been reported to range from $1.2 \%$ to $13.8 \%$ [10-13], although in neighbouring countries including Turkey [14], Pakistan [15] and Iraq [16] the reported rates are higher.

Cigarette smoking in adolescents is a complicated behaviour and a range of sociodemographic, environmental, behavioural and personal indicators are associated with adolescents' smoking status and transition through stages of smoking [17-20]. Besides, some risk factors can have different effects in different environments [21]. Therefore, the factors relating to the stages of cigarette smoking must be studied separately in each society so that preventive and control measures can be planned considering the extent of the problem and specific risk factors.
The majority of studies conducted in the Islamic Republic of Iran on adolescents' smoking have been cross-sectional and have mostly focused on the prevalence of smoking, age at smoking onset and determining the factors associated with attitudes towards smoking. Only 2 longitudinal studies, with limited sample sizes, were conducted to assess transition in cigarette smoking stages in adolescents in this country $[10,22]$. Moreover, smoking in adolescents is a latent variable [23] but this issue was not considered in any of the above mentioned studies. The aims of this longitudinal study were to use latent transition analysis (LTA) to determine the prevalence of smoking stages in a large sample of adolescents, the probability of transition across smoking stages and the personal and environmental predictors of transition.

\section{Methods}

\section{Study design and participants}

In this longitudinal, school-based study a representative sample of 10th-grade students in Tabriz (north-west of Islamic Republic of Iran) was assessed twice concerning their smoking behaviour. Participants completed a self-administered, multiple choice, anonymous questionnaire during November and December 2010. One year later (November and December 2011) the same questionnaire (with unnecessary parts excluded) was distributed to the same students in order to study changes in smoking behaviour. The reason for limiting the samples to 10th-grade students was the possibility to track them in the second phase of the study.

Out of about 865 classes 196 classes ( 82 and 114 boys and girls classes respectively) were randomly selected by considering the school type, the number of students in each school and the education major. All of the students of these classes were invited to participate in the study. More details about the sampling method of the study can be found elsewhere [24].

The respondents were assured about the voluntary nature of participation in the study and the confidentiality of the information before the questionnaire was distributed; furthermore they were asked not to provide their personal information in the questionnaire. This study and the related questionnaire were approved by the Eastern Azerbaijan Province Education Organization and the ethics committee of Tabriz University of Medical Sciences.

\section{Study tool}

The questionnaire was designed to gather information about the students' demographic characteristics, socioeconomic status, cigarette smoking behaviour, general risk-taking behaviour, substance abuse, self-esteem, self-injury and attitude towards cigarette smoking. Cigarette smoking behaviour was assess by an algorithm [25], self-esteem was measured using the Rosenberg 10-item questionnaire [26] and attitude toward smoking among the students was measured through 6 questions similar to Hill et al. [27]. More details about the validity and reliability of the questionnaire and definition of variables have been presented elsewhere [24].

\section{Data analysis}

LTA models were performed by using 4 indicator variables: smoking status (5 response categories); intention to smoke (5 response categories); smoking in the past month (2 response categories); and smoking in the past week (2 response categories). However, in assessing the predictors of transition in smoking stages, and because "intention to start smoking" was excluded in analyses due to inadequate sample size, LTA models with different numbers of latent statuses were performed and compared to determine the optimal statistical model. Relative model selection indices such as the Akaike information criterion (AIC) and Bayesian information 
criterion (BIC) were used to compare the relative fit of models with different numbers of latent statuses. We also considered parsimony and model interpretability to determine the optimal number of latent statuses. In all analyses, the criterion for stopping the iterative estimation procedure was maximum absolute deviation $(\mathrm{MAD}) \leq 0.000001$. Before choosing the best model of LTA, analyses were performed with random starting values. After identifying the most appropriate model, analyses were performed with specified starting values and parameter restriction techniques were used if necessary.

After finalizing the LTA model with 3 latent statuses, by using the likelihood ratio (LR) test, this model was compared with every other model in which predictors were entered univariately in the models. To select the appropriate predictors which should be entered in the final LTA model, we used forward and backward methods with the LR test. In the backward method, model fitting was started with all candidate predictor variables and improving the LTA model by deleting the variable(s) was tested with the LR test. This process was repeated until no further improvement was possible. In the forward method, model fitting was started with no predictor variables in the LTA model and improvements to the LTA model by adding the variable(s) was tested using the LR test. This process was repeated until no further improvement was possible. The results of these tests showed that the LTA model with all predictors except "type of school" was the optimal model.

The analyses were performed using SAS software, version 9.2, and PROC LTA software procedures for LTA.

\section{Results}

\section{Background characteristics}

Out of 5106 sampled students, 4903 participated in the study and filled out the questionnaire (response rate $96.1 \%$ ). From those who did not complete the questionnaire, 196 (3.8\%) studentswere absent and $7(0.2 \%)$ students did not participate in the study. After a 1-year follow-up, 843 (17.3\%) students dropped out of the study. The reasons for dropping out were absence on the day of data collection (43.2\%), school change (41.5\%), dropout from school (9.4\%) and unknown (5.9\%). No significant differences were found between the dropouts and the participants when comparing some of the key variables associated with cigarette smoking, such as attitude towards smoking [mean scores -10.2 (SD 3.3) versus - 10.4 (SD 3.2); $P=0.402]$, having smoker friends
( $18.9 \%$ versus $17.6 \% ; P=0.728)$, having a smoker in the family ( $40.3 \%$ versus $39.1 \%, P=0.844$ ) or positive history of substance abuse ( $1.5 \%$ versus $1.4 \% ; P$ $=0.731$ ).

Of the 4903 participants 2104 (42.9\%) were boys and 2799 (57.1\%) were girls. The mean age of students was 15.7 (SD 0.73) years (range 14-19 years). Table 1 shows the distribution of the students by the type of school and education major. It also shows the mean grades in the previous year, scores on self-esteem and scores on attitude toward cigarette smoking.

\section{Models with 9 latent statuses}

For performing LTA, the 4 observable variables (i.e. indicators) — smoking status, intention to smoking, smoking in the past month, and smoking in the past week - were used to assess smoking behaviour as a latent variable. With these indicators, and considering the 2 time periods, 10000 response patterns could be seen. We fitted LTA models with statuses ranging from 2 to 10 and for each LTA model $G^{2}$, AIC and BIC were computed. Table 2 compares these model selection statistics for these LTA models. According to the results of this table and interpretability of the results of models, we concluded that 9 latent statuses models were appropriate.

\begin{tabular}{|c|c|c|}
\hline Variable & \multicolumn{2}{|c|}{ Value } \\
\hline \multicolumn{3}{|l|}{ School type (no., \% of students) } \\
\hline Governmental & 4365 & 88.9 \\
\hline Nongovernmental & 542 & 11.1 \\
\hline \multicolumn{3}{|l|}{ Education major (no., \% of students) } \\
\hline Mathematics and physics & 1196 & 23.0 \\
\hline Empirical science & 1324 & 25.5 \\
\hline Humanities & 805 & 15.5 \\
\hline Technical and vocational; Work and knowledge & 1872 & 36.0 \\
\hline Previous year average grade [mean (SD) grade $]^{a}$ & \multicolumn{2}{|c|}{$16.6(2.2)$} \\
\hline Self-esteem [mean (SD) score] ${ }^{b}$ & \multicolumn{2}{|c|}{$17.8(4.8)$} \\
\hline Attitude to smoking [mean (SD) score $]^{k}$ & \multicolumn{2}{|c|}{$-10.2(3.2)$} \\
\hline
\end{tabular}

Possible score ranges: ${ }^{a}$ O to $20 ;{ }^{b} 70$ to 40 (higher score indicate lower self-esteem); ${ }^{-}-12$ to +12 .

$S D=$ standard deviation . 


\begin{tabular}{|c|c|c|c|c|c|c|}
\hline No. of latent statuses & $\begin{array}{l}\text { No. of parameters } \\
\text { estimated }\end{array}$ & $\mathbf{G}^{2}$ & df & $\begin{array}{l}\text { Maximum log- } \\
\text { likelihood }\end{array}$ & AIC & BIC \\
\hline 2 & 65 & 7483.1 & 9934 & -15268.9 & 7613.1 & 8039.2 \\
\hline 3 & 104 & 3708.2 & 9895 & -13381.5 & 3916.2 & 4598.0 \\
\hline 4 & 147 & 3192.7 & 9852 & -13123.7 & 3486.7 & 4450.4 \\
\hline 5 & 195 & 2785.7 & 9805 & -12920.2 & 3137.7 & 4445.5 \\
\hline 6 & 245 & 2482.7 & 9754 & -12768.8 & 2972.7 & 4578.9 \\
\hline 7 & 300 & 2341.8 & 9699 & -12698.3 & 2941.9 & 4908.6 \\
\hline 8 & 359 & 1359.2 & 9640 & -12306.9 & 2077.2 & 4430.7 \\
\hline 9 & 422 & 926.7 & 9577 & -11866.7 & 1770.7 & 4537.3 \\
\hline 10 & 489 & 1327.5 & 9510 & -12191.1 & 2305.4 & 5511.3 \\
\hline
\end{tabular}

$d f=$ degrees of freedom; $A / C=$ Akaike information criterion; $B / C=$ Bayesian information criterion.

The results of the selected model (LTA model with 9 statuses) are presented in Table 3. The top section of the table shows the prevalence of each latent status at baseline and after 12 months. It can be seen that $75.1 \%$ and $66.8 \%$ of students were in the committer stage (never smoked and sure never to start smoking) at the first and second time periods respectively. Moreover, $4.8 \%$ and $7.1 \%$ of the students were in the daily smoking stage in the first and second time periods respectively.

The second section of Table 3 shows the item-response probabilities, which were constrained to be equal at the two time periods and which form the basis for interpretation and labelling of the latent statuses. The higher conditional probability values $(\geq 0.50)$ are in bold font to highlight the overall pattern. All of the smoking stages (9 statuses) could be interpreted with respect to item-response probabilities. For example, the probabilities of being at the first status (committer) were $100 \%$ for those who had never smoked, 99.3\% for those who were confident that they would never start smoking in the future, $100 \%$ for those who had not smoked in the last month and 100\% for those who had not smoked in the last week.

Table 4 shows the transition probability matrix. This matrix expresses the probability of students being at each latent status at the second assessment who were in that latent status at the first assessment. For example, 88.1\% of committer students had remained in that status whereas $11.9 \%$ of them had transited to higher smoking stages. After 1 year, 10.4\% of students in the tried stage and $34.0 \%$ of students in the experimenter stage had transited to the daily smoking stage.

\section{Models with 3 latent statuses}

Although the sample size was large relatively $(n=4903)$, it was not sufficient to evaluate the predictors of transition in smoking stages (9 stages). Therefore, excluding 1 of the indicator variablesintention to start smoking - several LTA models were performed to find the appropriate model. With 3 indicator variables - smoking status, smoking in the past month and smoking in the past week - and considering the 2 time periods, 400 response patterns could be seen. We fitted LTA models with statuses ranging from 2 to 6 , and computed $\mathrm{G}^{2}$, AIC and BIC for each LTA model. According to the results of these model selection criteria and the interpretability of the results of models, the best model was selected. Table 5 shows the results of the selected model.

As before, the top part of Table 5 shows the prevalence of each latent status at the baseline and follow-up assessments. At the first assessment $79.1 \%$,
$15.6 \%$ and $5.3 \%$ of the students were in the never smoker, experimenter and regular smoker stages respectively. One year later, the percentage of never smokers had decreased to $69.8 \%$, while the percentage of experimenter and regular smokers had increased to $20.9 \%$ and 9.3\% respectively.

The second section of Table 5 shows that all 3 smoking stages were interpretable with respect to itemresponse probabilities. For example, the probability that regular smokers were daily or almost daily smokers was $61.2 \%$, had smoked in the past month was $93.8 \%$ and had smoked in the last week was $84.4 \%$.

In Table 6, the transition probability matrix shows that after 1 year, $10.1 \%$ and $1.7 \%$ of never smoker students had transited to the experimenter and regular smoking stages respectively. It is notable that $17.0 \%$ of experimenters had transited to the regular smoking stage.

After finalizing the LTA model with 3 latent statuses, by using the LR test, this model was compared with every other model in which predictors were entered univariately in the models. The results of these comparisons showed that all of the models with 1 predictor were better than the models without covariates. Table 7 shows the odds ratios of transition through stages by predictor variables. For example, being a boy 


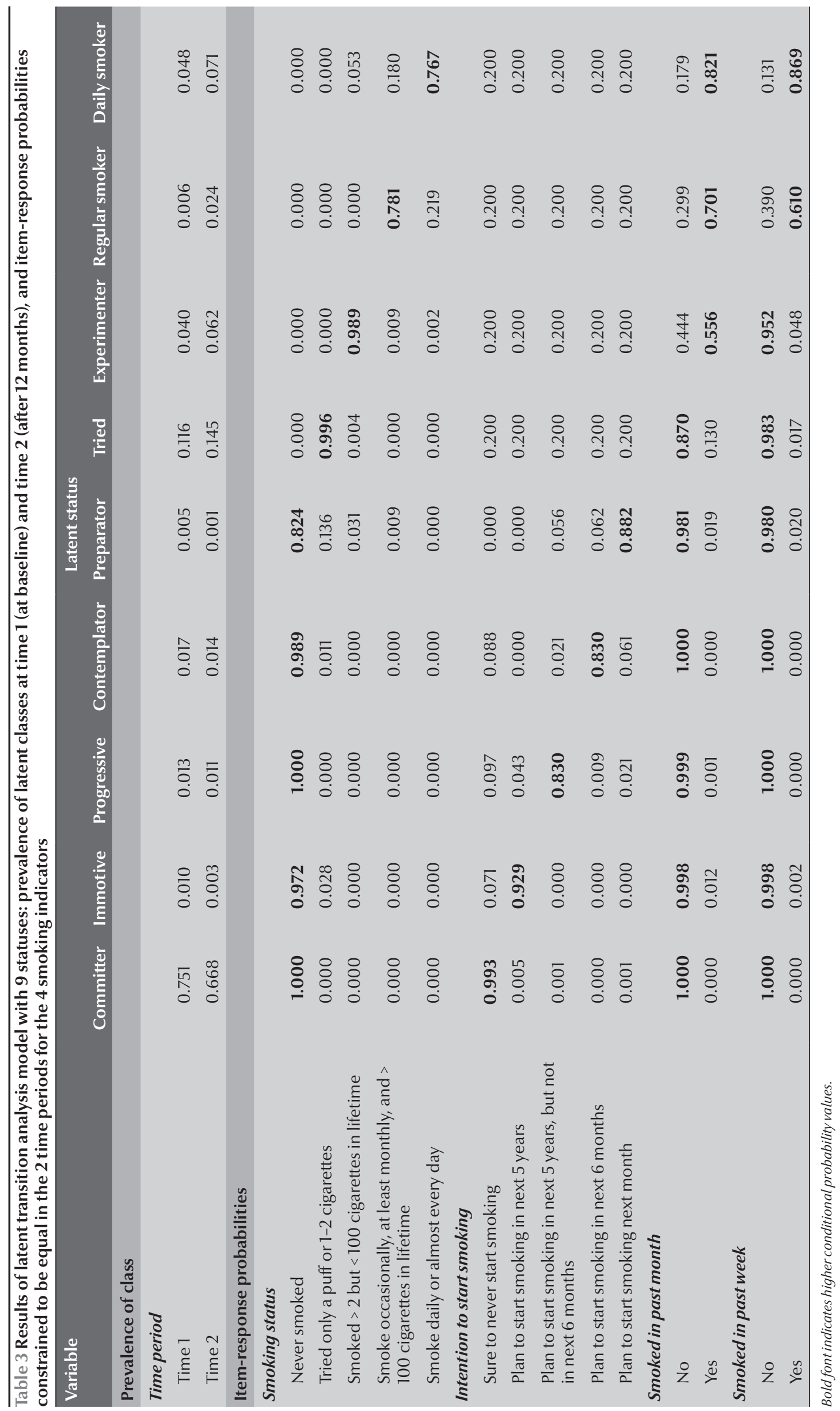




\begin{tabular}{|c|c|c|c|c|c|c|c|c|c|}
\hline \multirow{2}{*}{$\begin{array}{l}\text { Latent status at } \\
\text { time } 1\end{array}$} & \multicolumn{9}{|c|}{ Latent status at time 2} \\
\hline & Committer & Immotive & Progressive & Contemplator & Preparator & Tried & Experimenter & $\begin{array}{l}\text { Regular } \\
\text { smoker }\end{array}$ & $\begin{array}{l}\text { Daily } \\
\text { smoker }\end{array}$ \\
\hline Committer & 0.881 & 0.000 & 0.007 & 0.012 & 0.001 & 0.068 & 0.021 & 0.003 & 0.009 \\
\hline Immotive & 0.000 & 0.246 & 0.126 & 0.000 & 0.000 & 0.339 & 0.074 & 0.057 & 0.098 \\
\hline Progressive & 0.291 & 0.032 & 0.303 & 0.000 & 0.000 & 0.297 & 0.077 & 0.000 & 0.000 \\
\hline Contemplator & 0.000 & 0.000 & 0.070 & 0.326 & 0.000 & 0.231 & 0.028 & 0.000 & 0.345 \\
\hline Preparator & 0.583 & 0.000 & 0.000 & 0.000 & 0.062 & 0.355 & 0.000 & 0.000 & 0.000 \\
\hline Tried & 0.000 & 0.000 & 0.000 & 0.000 & 0.000 & 0.700 & 0.188 & 0.008 & 0.104 \\
\hline Experimenter & 0.000 & 0.000 & 0.000 & 0.000 & 0.000 & 0.000 & 0.557 & 0.103 & 0.340 \\
\hline Regular smoker & 0.000 & 0.000 & 0.000 & 0.000 & 0.000 & 0.000 & 0.000 & 0.899 & 0.101 \\
\hline Daily smoker & 0.000 & 0.000 & 0.000 & 0.000 & 0.000 & 0.000 & 0.000 & 0.336 & 0.664 \\
\hline
\end{tabular}

Bold font indicates higher conditional probability values.

increased the risk of transition from the never smoking stage to the experimenter stage by 2.78 -fold and to the regular smoking stage by 7.85 -fold, and having a history of self-injury increased the risk of transition from the never smoking to the experimenter by 2.03 -fold and to regular smoking by 2.83 -fold.

\section{Discussion}

The results of the LTA revealed that the model with 9 statuses was appropriate for our data. All of the 9 smoking stages could be interpreted with respect to item-response probabilities. For example, probabilities of being at the first stage (committer) were 100\% in who had never smoked, $99.3 \%$ in those confident that they would never start smoking and $100 \%$ in those who had not smoked in the last month or last week. These results are in harmony with the results of the latent class analysis of our data [25].

\begin{tabular}{|c|c|c|c|}
\hline \multicolumn{4}{|c|}{$\begin{array}{l}\text { Table } 5 \text { Results of latent transition analysis model with } 3 \text { statuses: prevalence of latent classes at time } 1 \text { (at baseline) and } \\
\text { time } 2 \text { (after } 12 \text { months), and item-response probabilities constrained to be equal in the } 2 \text { time periods for the } 4 \text { smoking } \\
\text { indicators }\end{array}$} \\
\hline \multirow[t]{2}{*}{ Variable } & \multicolumn{3}{|c|}{ Latent status } \\
\hline & Never smoker & Experimenter & Regular smoker \\
\hline \multicolumn{4}{|l|}{ Prevalence of class } \\
\hline \multicolumn{4}{|l|}{ Time period } \\
\hline Time 1 & 0.791 & 0.156 & 0.053 \\
\hline Time 2 & 0.698 & 0.209 & 0.093 \\
\hline \multicolumn{4}{|l|}{ Item-response probabilities } \\
\hline \multicolumn{4}{|l|}{ Smoking status } \\
\hline Never smoked & 0.999 & 0.016 & 0.018 \\
\hline Tried only a puff or $1-2$ cigarettes & 0.000 & 0.770 & 0.035 \\
\hline Smoked $>2$ but $<100$ cigarettes in lifetime & 0.000 & 0.212 & 0.026 \\
\hline $\begin{array}{l}\text { Smoke occasionally, at least monthly, and > } 100 \text { cigarettes } \\
\text { in lifetime }\end{array}$ & 0.001 & 0.002 & 0.309 \\
\hline Smoke daily or almost every day & 0.000 & 0.000 & 0.612 \\
\hline \multicolumn{4}{|l|}{ Smoked in past month } \\
\hline No & 0.999 & 0.941 & 0.062 \\
\hline Yes & 0.001 & 0.059 & 0.938 \\
\hline \multicolumn{4}{|l|}{ Smoked in past week } \\
\hline No & 0.999 & 0.974 & 0.156 \\
\hline Yes & 0.001 & 0.026 & 0.844 \\
\hline
\end{tabular}

Bold font indicates higher conditional probability values. 


\begin{tabular}{lccc}
\hline $\begin{array}{l}\text { Table } 6 \text { Results of latent transition analysis model with } 3 \text { statuses: probabilities of } \\
\text { transition between statuses at time } \mathbf{1} \text { (at baseline) and time } \mathbf{2} \text { (after 12 } \\
\text { months) }\end{array}$ \\
\begin{tabular}{|cccc}
\hline Latent status at time 1 & Latent status at time 2 \\
& Never smoker & Experimenter & Regular smoker \\
Never smoker & $\mathbf{0 . 8 8 2}$ & 0.101 & 0.017 \\
Experimenter & 0.000 & $\mathbf{0 . 8 3 0}$ & 0.170 \\
Regular smoker & 0.000 & 0.000 & $\mathbf{1 . 0 0 0}$ \\
\hline
\end{tabular}
\end{tabular}

Bold font indicates higher conditional probability values.

We found that $75.1 \%$ and $66.8 \%$ of students were at the committer stage at the first assessment (at baseline) and second assessment (after 12 months) respectively. Among never smoker students (if we consider only students in the first 5 stages), $94.3 \%$ at baseline and $95.8 \%$ at the end of the study were committers. In the United States, Hong et al. found that $90.9 \%$ of non-smoker high-school students were in the no smoking intent group [28]. In another study in the USA, $55 \%$ of non-smokers (ages 12-18 years) had low intention to smoke [29]. Kremers et al., studying a large sample with mean age of 13.3 years in 6 European countries, reported that $34.9 \%$ of never smoker subjects were at the committer stage [30]. The observed differences may be due to differences in definitions and measurement tools and the age of the study samples.

The results of the LTA model with 3 indicators showed that at the baseline of the study, the prevalence of experimenters and regular smokers were $15.6 \%$ and $5.3 \%$ respectively, rising to $20.9 \%$ and $9.3 \%$ after 12 months. The prevalence of smoking in our samples was lower compared with other countries; $20 \%$ of adolescents in the USA [31], 30\% of adolescents in Hong Kong (age range $18-13$ years) [32], $8.9 \%$ of students (mean age 13.6 years) in London [33],

\begin{tabular}{|c|c|c|c|}
\hline \multirow[t]{2}{*}{ Variable } & \multicolumn{3}{|c|}{ Latent status transition } \\
\hline & $\begin{array}{l}\text { Never smoker to } \\
\text { experimenter }\end{array}$ & $\begin{array}{l}\text { Never smoker to } \\
\text { regular smoker }\end{array}$ & $\begin{array}{c}\text { Experimenter to regular } \\
\text { smoker }\end{array}$ \\
\hline Intercept (odds) & 0.02 & 0.001 & 0.31 \\
\hline Sex (being boy) & 2.78 & 7.85 & 8.30 \\
\hline Age (higher age) & 1.05 & 1.10 & 1.19 \\
\hline \multicolumn{4}{|l|}{ Education major } \\
\hline Mathematics and physics & 1.00 & 1.00 & 1.00 \\
\hline Empirical science & 1.45 & 1.12 & 1.63 \\
\hline Humanities & 1.15 & 0.99 & 2.19 \\
\hline Technical and vocational; Work and knowledge & 1.28 & 3.37 & 2.18 \\
\hline Average school grade (higher grade) & 0.95 & 0.97 & 0.94 \\
\hline \multicolumn{4}{|l|}{ Socioeconomic status } \\
\hline Very low & 1.00 & 1.00 & 1.00 \\
\hline Low & 0.89 & 1.22 & 0.92 \\
\hline Middle & 0.83 & 1.10 & 0.69 \\
\hline High & 1.16 & 1.76 & 0.62 \\
\hline Very high & 1.09 & 1.02 & 2.71 \\
\hline Living with parents & 0.70 & 0.92 & 0.48 \\
\hline Having smoker in the family & 1.33 & 1.02 & 1.52 \\
\hline Having smoker friend & 1.65 & 1.83 & 1.99 \\
\hline Lower self-esteem & 1.03 & 1.04 & 1.01 \\
\hline \multicolumn{4}{|l|}{ Attitude to smoking score } \\
\hline-12 & 1.00 & 1.00 & 1.00 \\
\hline-9 to -11 & 2.10 & 1.63 & 3.42 \\
\hline$>-9$ & 3.42 & 3.29 & 4.56 \\
\hline Substance abuse & 0.99 & 1.12 & 6.65 \\
\hline Having general risk-taking behaviours & 1.66 & 1.83 & 0.56 \\
\hline Self-injury & 2.03 & 2.81 & 1.01 \\
\hline
\end{tabular}


and $19 \%$ of male and $17 \%$ of female adolescents in Australia [34] were reported to be regular smokers. Studies of cigarette smoking status in Iranian students have reported the prevalence of smoking to be $1.2 \%$ to $13.8 \%$. Reasons for such a wide range include differences in the definitions of being a smoker, age distribution in the study samples and locations where the research was conducted [10-12,35-38]. The prevalence of cigarette smoking in adolescents of neighbouring countries are higher; for example in Turkey more than 15\% [14], in Pakistan 13.7\% [15] and in Iraq 15.3\% (25.1\% and 2.7\% in boys and girls respectively) [16] of adolescents reported being daily smokers. The lower prevalence of regular smoking reported in the current study in comparison with recent studies in the Islamic Republic of Iran may be due to the fact that the sample comprised only 10th-grade students.

The results of this study indicated that after 1 year the percentage of never smokers declined from $79.1 \%$ to $69.8 \%$ and the percentage of experimenter and regular smoker increased from $15.6 \%$ and $5.3 \%$ to $20.9 \%$ and $9.3 \%$ respectively. Furthermore after 1 year, $10.1 \%$ and $1.7 \%$ of the never smokers had become experimenters and regular smokers respectively, whereas $17 \%$ of experimenters had become regular smokers. In a study in Shiraz, Ayatollahi et al. revealed that after 8 months $11.4 \%$ and $2.2 \%$ of never smoker students had transited to experimenter and regular smoking stages respectively and that $14.5 \%$ of the students at the experimenter stage had transited to regular smoking stage [22]. In another study in the Islamic Republic of Iran, Mohammadpoorasl et al. showed that after 1 year $14.3 \%$ and $2.8 \%$ of never smoker students had transited to experimenter and regular smoking stages respectively and $16.5 \%$ of the students at the experimenter stage had transited to regular smoking [10]. The results of Hoving et al's study in 6 European countries indicated that $7 \%$ of never smoker adolescents, with the mean age of 13.3 years, had transited to smoking monthly or more often at 1-year follow-up [39].

Our results showed that being male increased the risk of transition from never smoker to experimenter and regular smoker about 3- and 8-fold respectively, and also increased the risk of transition from experimenter to regular smoker more than 8-fold. In general, studies have shown that the smoking rate in men is higher than in women. Differences in smoking rates between men and women in the European countries and the USA have reduced, however, particularly in adolescents. Yet in the Eastern Mediterranean, South Asia and Western Pacific regions, smoking rates among male adolescents are still much higher than among girls $[40,41]$.

It is expected that older students would belong to more advanced stages of cigarette smoking $[11,19,32,42]$. However, Mohammadpoorasl et al. showed that in multivariable analysis, the age of students had no role in transition between smoking stages [10]. The results of the present study showed that despite low age variation in the study sample (SD 0.7 years), the age of students had a significant role in transition between smoking stages.

The results of the LTA model with covariates showed that besides sex and age, other variables were associated with transition between smoking stages: education major, average examination scores, socioeconomic status, living with parents, having a smoker in the family, having a smoker friend, lower self-esteem, attitude toward smoking, substance abuse, having general risk taking behaviours and self-injury. These results are similar to previous studies focusing on variables such as having general risk-taking behaviours $[10,11,17]$, having a smoker in the family $[11,43,44]$, having a smoker friend $[10,17,42]$, substance abuse $[10,11,17]$, attitude toward smoking $[10,11,45,27]$ and lower self-esteem [19]. In contrast with the results of the present study, a previous study indicated that socioeconomic status, living with parents and self-injury were not associated with transition between smoking stages in a multivariable model [46]. Although when we entered the socioeconomic status variable as a covariate, the LTA model was improved, contradictory results were seen for various levels of the socioeconomic status.

Several aspects of this study can limit the application of the findings. First, despite using quite satisfactory methodology and sampling methods, generalization of the study results is limited due to the fact that this study was limited to 10th grade students of Tabriz city. Secondly, the study relied on self-reported data. Thirdly, the predictors were only evaluated at the beginning of the study and could have changed during the period of the followup. Fourthly, the relationship between a predictor variable and the transition between smoking stages can be evaluated with comparison of LTA models with and without predictor variable, but the results of analysis did not provide $P$-value and confidence intervals for odds ratios, which may limit discussion about odds ratios especially when they are very close to 1.0 .

\section{Conclusion}

The incidence of becoming a cigarette smoker among adolescents in our study was very high. Our findings are in favour of taking preventive measures in the adolescence and pre-adolescence periods. Being male, higher age, having a smoker in the family, having smoker friends, lower self-esteem, attitude toward smoking, substance abuse and having general risk-taking behaviours were associated with a higher probability of transition to higher smoking stages. More studies about the adolescent population are necessary to support the observed results of this study and thus allow for 
a certain generalization of the observations. Qualitative studies are needed to further investigate smoking stages, especially the sub-stages of the precontemplation stage, in our country. The identification of the variables affecting the stages of smoking acquisition is only a first step toward a better understanding of the smoking phenomenon among adolescents. However, the content of smoking prevention programmes for adolescents should be based on these risk factors and adapted to each stage of smoking acquisition.

\section{Acknowledgements}

We wish to thank all of the students, teachers, and principals of Tabriz high schools for their valuable collaboration. Funding: This study was a $\mathrm{PhD}$ thesis supported by Tehran University of Medical Sciences. We would like to thank the Deputy of Research and Technology of Tehran University of Medical Sciences and the Deputy of Research of Tabriz University of Medical Sciences for their financial support.

Competing interests: None declared.

\section{References}

1. Thun MJ et al. Lung cancer occurrence in never-smokers: an analysis of 13 cohorts and 22 cancer registry studies. PLoS Med, 2008, 5(9):e185. doi:10.1371/journal.pmed.0050185.

2. Annual smoking-attributable mortality, years of potential life lost, and economic costs-United States, 1995-1999. Morbidity and Mortality Weekly Report, 2002, 51:300-303.

3. Novotny TE. Tobacco use. In: Brownson RC, Davis JR, eds. Chronic disease epidemiology and control. Baltimore, Maryland, American Public Health Association, 1993:199-220.

4. Breslau N, Peterson EL. Smoking cessation in young adults: age at initiation of cigarette smoking and other suspected influences. American Journal of Public Health, 1996, 86:214220

5. Pierce JP, Gilpin E. How long will today's new adolescent smoker be addicted to cigarettes? American Journal of Public Health, 1996, 86:253-256.

6. Stanton WR. DSM-III-R tobacco dependence and quitting during late adolescence. Addictive Behaviors, 1995, 20:595-603.

7. Taioli E, Wynder EL. Effect of the age at which smoking begins on frequency of smoking in adulthood. New England Journal of Medicine, 1991, 325:968-969.

8. Huang $M$ et al. Stages of smoking acquisition versus susceptibility as predictors of smoking initiation in adolescents in primary care. Addictive Behaviors, 2005, 30:1183-1194.

9. The Global Youth Tobacco Survey Collaborative Group. Tobacco use among youth: a cross country comparison. Tobacco Control, 2002, 11:252-270.

10. Mohammadpoorasl A et al. Transitions between the stages of smoking in Iranian adolescents. Preventive Medicine, 2011, 52:136-138.

11. Alireza Ayatollahi S, Mohammadpoorasl A, Rajaeifard A. Predicting the stages of smoking acquisition in the male students of Shiraz's high schools, 2003. Nicotine and Tobacco Research, 2005, 7:845-851.

12. Kelishadi $\mathrm{R}$ et al. Smoking behavior and its influencing factors in a national-representative sample of Iranian adolescents: CASPIAN study. Preventive Medicine, 2006, 42:423-426.

13. Azaripour MH. I.R. Iran Global Youth Tobacco Survey (GYTS) report. World Health Organization Regional Office for the Eastern Mediterranean, 2007 [Internet]. http://www.who.int/ tobacco/surveillance/country_reports_emro/en/, accessed 24 February 2014).

14. Bilir N et al. Tobacco control in Turkey: story of commitment and leadership. Copenhagen, World Health Organization Regional Office for Europe, 2012.

15. Rozi S, Akhtar S. Smoking among high school adolescents in Karachi, Pakistan. International Journal of Epidemiology, 2004, 33:613-614.
16. Siziya S, Muula AS, Rudatsikira E. Correlates of current cigarette smoking among in-school adolescents in the Kurdistan region of Iraq. Conflict and Health, 2007, 1:13.

17. Kaplan $\mathrm{CP}$ et al. Smoking acquisition among adolescents and young Latinas: the role of socioenvironmental and personal factors. Addictive Behaviors, 2001, 26:531-550.

18. Turner L, Mermelstein R, Flay B. Individual and contextual influences on adolescent smoking. Annals of the New York Academy of Sciences, 2004, 1021:175-197.

19. Tyas SL, Pederson LL. Psychosocial factors related to adolescent smoking: a critical review of the literature. Tobacco Control, 1998, 7:409-420.

20. Moolchan ET, Ernst M, Henningfield JE. A review of tobacco smoking in adolescents: treatment implications. Journal of the American Academy of Child and Adolescent Psychiatry, 2000, 39(6):682-693.

21. Novak SP, Clayton RR. The influence of school environment and self-regulation on transitions between stages of cigarette smoking: a multilevel analysis. Health Psychology, 2001, 20:196-207.

22. Ayatollahi SA, Mohammadpourasl A, Rajaeifard A. Psychological predictors of transition in different stages of cigarette smoking. Journal of Ardabil University of Medical Sciences, 2005, 4(14):13-19 [in Farsi].

23. Pallonen UE et al. Stages of acquisition and cessation for adolescent smoking: an empirical integration. Addictive Behaviors, 1998, 23:303-324.

24. Mohammadpoorasl A et al. Smoking stages in an Iranian adolescent population. Acta Medica Iranica, 2012, 50:746-754.

25. Mohammadpoorasl A et al. An algorithm of smoking stages assessment in adolescents: a validation study using the latent class analysis model. International Journal of Preventive Medicine, 2013, 4(11):1304-1311.

26. Rosenberg M. Society and the adolescent self-image. Princeton, New Jersey, Princeton University Press, 1965.

27. Hill AJ et al. Predicting the stages of smoking acquisition according to the theory of planned behavior. Journal of Adolescent Health, 1997, 21:107-115.

28. Hong JY et al. [Related factors for the initiation of smoking in high school students based on the transtheoretical model]. Journal of Preventive Medicine and Public Health, 2006, 39:6773 [in Korean].

29. Tyc VL et al. Predictors of smoking intentions and smoking status among nonsmoking and smoking adolescents. Addictive Behaviors, 2004, 29(6):1143-1147.

30. Kremers SP et al. Motivational stages of adolescent smoking initiation: predictive validity and predictors of transitions. $A d$ dictive Behaviors, 2004, 29:781-789. 
31. Cigarette use among high school students-United States, 1991-2009. Morbidity and Mortality Weekly Report, 2010, 59(26):797-801.

32. Lam TH, Stewart SM, Ho LM. Prevalence and correlates of smoking and sexual activity among Hong Kong adolescents. Journal of Adolescent Health, 2001, 29:352-358.

33. Best $\mathrm{D}$ et al. Drinking and smoking as concurrent predictors of illicit drug use and positive drug attitudes in adolescents. Drug and Alcohol Dependence, 2000, 60:319-321.

34. White V, Hayman J. Smoking behaviours of Australian secondary students in 2005. Melbourne, Victoria, Centre for Behavioural Research in Cancer, Cancer Control Research Institute, 2006.

35. Ramezankhani A et al. [Pattern of cigarette smoking in adolescent students in Tehran]. Pejouhandeh, 2010, 15(75):115-122 [in Farsi].

36. Namakin K, Sharifzadeh GR, Miri MR. Prevalence of cigarette smoking and evaluation of attitude and knowledge in its high school boys in Birjand, 2005. Journal of Birjand University of Medical Sciences, 2008, 15(1):66-70 [in Farsi].

37. Agha Molaei T, Zare S. [Cigarette and hookah using pattern in over-15 population of Bandar Abbas, a population based study]. Medical Journal of Hormozgan University, 2008, 11:241246 [in Farsi].

38. Ziaee $\mathrm{P}$ et al. [A study on prevalence of cigarette smoking and the age of first smoking in senior high school students in Tehran 1998-99]. Hakim, 2001, 4:78-84 [in Farsi].
39. Hoving C, Reubsaet A, de Vries H. Predictors of smoking stage transitions for adolescent boys and girls. Preventive Medicine, 2007, 44(6):485-489.

40. Warren CW et al. Patterns of global tobacco use in young people and implications for future chronic disease burden in adults. Lancet, 2006, 367:749-753.

41. Morley KI, Hall WD. Explaining the convergence of male and female smoking prevalence in Australia. Addiction, 2008, 103:487-495.

42. Mayhew KP, Flay BR, Mott JA. Stages in the development of adolescent smoking. Drug and Alcohol Dependence, 2000, 59(Suppl. 1):S61-S81.

43. Komro KA et al. Parental, family, and home characteristics associated with cigarette smoking among adolescents. American Journal of Health Promotion, 2003, 17:291-299.

44. Simons-Morton B et al. Latent growth curve analyses of peer and parent influences on smoking progression among early adolescents. Health Psychology, 2004, 23:612-621.

45. Andrews JA, Duncan SC. The effect of attitude on the development of adolescent cigarette use. Journal of Substance Abuse, 1998, 10:1-7.

46. Mohammadpoorasl A et al. Predictors of transition in different stages of smoking: a longitudinal study. Journal of Addiction and Health, 2010, 1:1-8. 